\title{
NEGOCIACIÓN A LA FRANCESA: UN ENFOQUE CUALITATIVO"
}

\author{
Enrique Ogliastri:* \\ María Isabel Rendón ${ }^{* * * *}$ \\ Sébastien Michel Fosse
}

* doi: 10.11144/Javeriana.cao30-54.nfec. Este artículo tuvo financiación parcial del Comité de Investigación de la Facultad de Administración de UniAndes, y del Comité de Investigación de INCAE. Los autores agradecen al investigador Mauricio Rivera, a los entrevistadores y a los dos centenares de entrevistados. El artículo se recibió el 30/01/2017 y se aprobó el 15/05/2017. Sugerencia de citación: Ogliastri U., E., Rendón, M. I., Fosse, S. M. (2017). Negociación a la francesa: un enfoque cualitativo. Cuadernos de Administración, 30(54), 91-123. http://dx.doi.org/10.11144/Javeriana.ca030-54.nfec.

** Ph. D. en Teoría de la Organización, Northwestern University, Evanston, Estados Unidos, 1973. Profesor titular del Instituto de Empresa, Madrid, España, y de INCAE Business School, Costa Rica.

Correo electrónico: enrique.ogliastri@ie.edu

*** Maestría en Administración, Universidad de Los Andes, Bogotá, Colombia, 2004. Licenciatura en Diseño Industrial, Universidad Javeriana, Bogotá, Colombia, 1996. Asesora de estrategia para la Cámara de Comercio de Cartagena, Colombia.

Correos electrónicos: m.rendon38@uniandes.edu.co y rendonmir@gmail.com

**** Ph.D. en Comportamiento Organizacional, Instituto de Empresa, Madrid, España, 2012. Profesor-Investigador en la Deusto Business School, Universidad de Deusto, Bilbao, España. Profesor visitante en la Universidad EAN, Bogotá, Colombia

Correo electrónico: sebastien.m.fosse@gmail.com 


\section{Negociación a la francesa: un enfoque cualitativo}

\section{Resumen}

Con base en las teorías de Hall, Hofstede y el estudio Globe, este artículo analiza, de un lado, la manera de negociar de los franceses y una interpretación de por qué negocian así, y de otro, los retos que afrontan personas de otras culturas al negociar con ellos. Se utilizan metodologías cualitativas inductivas y comparativas, sobre experiencias concretas de negociación con franceses: un grupo focal y tres estudios con entrevistas semiestructuradas con 244 negociadores de cinco continentes. A quienes van a negociar con los franceses, se recomienda preparar la negociación con datos y argumentos sólidos, buscar un acercamiento gradual, ser asertivo pero flexible y mantener la formalidad y las buenas maneras.

\section{Palabras clave: Francia, negociación, cultura, método cualitativo, Latinoamérica. \\ Clasificación JEL: $\mathrm{F}_{51}$}

\section{French negotiation style: A qualitative approach}

\section{Négociation à la Française: une approche qualitative}

\section{ABSTRACT}

Based on theories developed by Hall, Hofstede, and the Globe project, this article analyzes, on one hand, the patterns of French negotiators, and on the other hand, the challenges that people from other cultures face when they negotiate with the French. Inductive, comparative and qualitative methodologies are used about specific negotiation experiences with the French: a focus group and three studies with semi-structured interviews with 244 negotiators from five continents. To those negotiating with the French, it is advised to prepare negotiations with facts, figures and solid arguments, to look for a gradual approach, to be assertive but flexible, and to maintain formality and good manners at the negotiation table.

Key words: France, negotiation, culture, qualitative methods, Latin America.

JEL Classification: $F_{51}$

\section{RÉSUMÉ}

Basé sur les théories de Hall, Hofstede, et l'étude Globe, cet article analyse, d'une part, la manière de négocier des Français et les raisons pour lesquelles ils négocient ainsi, et, d'autre part, les défis cultureIs auxquels sont confrontés les individus qui négocient avec eux. II applique des méthodologies qualitatives inductives et comparatives à des expériences concrètes de négociation avec des Français, à savoir : un groupe de discussion, et trois études comportant des entretiens semi-structurés avec 244 négociateurs des cinq continents. A ceux qui vont négocier avec les Français, il est recommandé de préparer la négociation avec des données et arguments solides, de rechercher une approche progressive, d'être assertif mais flexible, et de maintenir la formalité et les bonnes manières.

Mots-clés: France, négociation, culture, méthode qualitative, Amérique Latine. Classification JEL: $\mathrm{F}_{5}$ 
Este artículo presenta las actitudes, costumbres y acciones generalmente utilizadas por los franceses para desarrollar negociaciones, con el fin de esclarecer la cultura de negocios en Francia, tema que es particularmente importante ahora que este país ha recuperado su puesto como quinta economía del mundo y es un eje de la Unión Europea (Giles, 2016). En medio de la globalización económica, esta posición internacional significativa de las empresas francesas (especialmente en sectores como el turismo, los aeronaves y la moda) aumenta la probabilidad de interacciones con negociadores de otros países, y por consiguiente de "fricciones culturales" (Luo y Shenkar, 2011), que pueden generar pérdida de esfuerzo, tiempo y recursos si no se tiene un buen conocimiento de la cultura francesa. A la inversa, construir una relación sólida con los negociadores franceses puede ser una fuente significativa de beneficios mutuos.

El estudio sigue la nueva teoría de negociación que se ha venido desarrollando en las últimas décadas (Malhotra y Bazerman, 2008; Raiffa, 1982; Ury, Fisher y Patton, 2011; Walton y McKersie, 1991) y que contrapone un sistema de negociación esencialmente orientado a distribuir valor mediante el regateo, con la negociación "integrativa" que trabaja en la creación de valor mutuo y en la distribución de valor mediante criterios objetivos. Se entiende por negociación el proceso que siguen dos o más partes para llegar a un acuerdo que resuelve sus diferencias y les deja mejor de lo que estaban; se trata de un comportamiento aprendido, principalmente las costumbres y acciones que son consideradas normales en una región.

Los conceptos sobre negociación y sobre la cultura francesa se utilizan en el análisis de los datos obtenidos, con una metodología inductiva y cualitativa. El estudio se basa en datos cualitativos (palabras, frases), procesados de manera inductiva que va de las experiencias concretas a las generalizaciones (Glaser y Strauss, 1967). La investigación se encuadra dentro de una teoría de la práctica (Bourdieu, 1977), que usa la experiencia como fuente para la teorización y la investigación en negociaciones (Broome, 2017). Este paradigma integra teoría, investigación, práctica y enseñanza (Ebner y Parlamis, 2017).

Este artículo se divide en cinco secciones. La primera presenta la literatura sobre negociación y cultura en Francia; la segunda, el estudio realizado; la tercera, los resultados obtenidos sobre el estilo francés de negociación. La cuarta identifica la secuencia o proceso ideal que se quiere seguir en la cultura francesa, así como una interpretación sobre por qué negocian así. Quinto, las experiencias y recomendaciones de los extranjeros que han negociado en Francia. Y finalmente, las conclusiones. 


\section{Esquemas conceptuales sobre cultura y negociación: la contradictoria cultura francesa}

En las últimas décadas se han estudiado con más frecuencia las diferencias culturales, y el autor más citado y conocido es Hofstede (2003). El estudio Globe en la misma línea de Hofstede, aporta conclusiones sobre las regiones culturales del mundo y establece diferencias entre la cultura actual y la ideal. Sobre la relación entre cultura y negociación también hay una extensa literatura (Adair et al., 2004; Brett, 2014; Brett et al., $1998,2007,2017)$. La cultura se forma con los comportamientos aprendidos, al igual que la negociación. Desde los estudios de Graham et al. $(1988 ; 1994)$, sabemos que el estilo francés de negociación es distinto de los demás por la importancia del estatus del negociador y del contexto cultural. El contexto cultural francés ha sido objeto de varios trabajos científicos, incluyendo monografías (Hall y Hall, 1990), estudios etnográficos (Crozier, 1964; D'Iribarne, 1994), y trabajos que combinan perspectivas cuantitativas y cualitativas (Castel et al., 2007). Varios autores propusieron descripciones del estilo francés de negociación (Cogan, 2003; Gannon y Pillai, 2012; Morrison y Conaway, 2006; Newson-Balle, 1996; van der Walt, 2010); sin embargo, aunque muy interesantes, estas descripciones de cómo negocian los franceses han fraccionado el tema en variables, en lugar de un enfoque integral sobre el estilo francés de negociación.

Para contribuir a llenar esta carencia, aquí se propone una descripción sistemática de la negociación francesa, con datos de primera mano y un enfoque cualitativo e interpretativo: entrevistas y narrativas estructuradas sobre una experiencia concreta de negociación en la cual una de las partes era francesa y la otra parte no era francesa (africano, asiáticos, europeos, latinoamericanos, norteamericanos).

La cultura francesa muestra contradicciones internas que dificultan su clasificación, por ejemplo, Brett el al. (1998, p. 64) la consideran un “enigma cultural”, y Castel et al. (2007, p. 547) concluyen que es una cultura "universalista" pero que hace demasiadas excepciones. Primero se va a abordar en detalle el análisis comparativo de Hofstede (2003), donde Francia aparece de forma bastante peculiar.

Un ejemplo de la paradoja francesa se relaciona con la tradicional oposición entre jerarquía e igualitarismo. Según Hofstede, la jerarquía, se traduce en la distancia de poder, el grado en que las personas aceptan una distribución desigual del poder (Hofstede, 2003; Hofstede et al., 2010). En esta clasificación, Francia está en el tercio superior, 
en el mismo grupo que varios países de América Latina y algunos de Asia (como China o Japón). La cultura francesa aparece, entonces, como una cultura de gran distancia de poder.

Si en la cultura francesa se observa una gran distancia de poder, se podría esperar que también se destacara por su aceptación de las desigualdades. Sorprendentemente, las estadísticas no validan esta idea. De hecho, respecto al igualitarismo, o el reconocimiento de las personas como iguales morales, Francia se encuentra, de nuevo, en la parte más alta de la comparación (Schwartz, 1994; 1999). Así, la cultura francesa es a la vez jerárquica e igualitaria, como observó Hofstede (2003).

En las otras dimensiones del modelo de Hofstede, Francia aparece también de forma particular y paradójica. Aunque una distancia de poder alta es normalmente asociada a una orientación hacia el grupo (y no al individuo), la cultura francesa muestra un nivel alto de individualismo. Según Hofstede, solo se encuentra este tipo de combinación en cuatro países europeos. Con esta combinación de un nivel alto de distancia de poder y de individualismo, se destaca la cultura francesa por su "individualismo estratificado" (Hofstede et al., 2010, p. 104).

Respecto a la dimensión del rechazo de la incertidumbre, que opone la voluntad de controlar el futuro con un enfoque más pasivo, Francia también se destaca por lo singular. Con una puntuación muy alta, la cultura francesa prefiere el control del futuro. De hecho, a los franceses no les gustan las sorpresas, para ellos la planificación y las normas son muy importantes. Esta preocupación por el control se traduce en una capacidad para desarrollar sistemas complejos de alto riesgo, donde se evitan errores (organizaciones de alta confiabilidad) (Perrow, 1999; sobre América Latina ver Ogliastri y Zúñiga, 2016), lo que sostiene una posición de excelencia en sectores como la industria nuclear, la producción de trenes de alta velocidad y la industria aeronáutica. Como anotara Hofstede (2016), una alta puntación del rechazo a la incertidumbre combinada con un nivel alto de distancia del poder, en la sociedad francesa, hace que quienes tienen el poder no se sientan obligados a seguir todas las reglas que atan a la gente de la calle.

Respecto a la orientación a largo plazo, es decir, la medida en la cual la sociedad mantiene vínculos con respecto a los retos del presente y del futuro, la cultura francesa aparece relativamente alta, en el primer tercio de orientación a largo plazo (Hofstede et al., 2010); los franceses muestran pragmatismo en su observación de las tradiciones, que 
suelen adaptar al contexto. Por ejemplo, en el actual régimen político francés, desde su instalación en 1958 por Charles de Gaulle, el Presidente, aun elegido por el sufragio universal, tiene el rol de un "monarca republicano" (Duverger, 1974). Así se integra la larga historia monárquica de Francia al régimen político dominante en Europa; la democracia parlamentaria.

Finalmente, respecto a la última dimensión del modelo de Hofstede, la masculinidad/feminidad o como la sociedad está impulsada por el rendimiento-éxito, o la empatía-calidad de vida, la cultura francesa se presenta como femenina. Esta orientación se manifiesta por la importancia del sistema estatal de bienestar, su número relativamente bajo de días laborables y la importancia dada a la calidad de vida (Hofstede et al., 2010). También respecto a esta dimensión aparece una excepción: la cultura francesa es la única donde los estratos más altos de la sociedad son orientados a la feminidad, mientras los estratos de nivel medio se enfocan a la masculinidad (Hofstede, 2016).

En el estudio Globe se compara la cultura actual con la ideal; Francia aparece dentro de una desviación estándar del promedio mundial en 14 de las 18 escalas medidas. Las principales diferencias entre lo actual y lo ideal son un deseo de tener menor distancia de poder o jerarquía en la sociedad francesa, y por un mayor grado de asertividad, de orientación al futuro y de ser más humanitarios (Castel et al., 2007).

Hall (1966) y Hall y Hall (1990) ofrecen otros esquemas para diferenciar culturas, en particular los conceptos de tiempo monocrónico o policrónico, y la existencia de un contexto comunicativo importante en las relaciones. Las culturas orientadas a hacer una sola cosa a la vez, manejan agendas precisas y ordenadas, como en Francia. El contexto comunicativo "alto" implica que es importante no solo lo que se dice, sino cómo y cuándo se dice, así como la comunicación no verbal. La cultura francesa parece decantarse hacia el "bajo" contexto comunicativo, que valora la precisión del idioma y lograr acuerdos escritos que eviten ambigüedades.

La cultura francesa también se ha examinado a través de los conceptos de culturas de dignidad, de honor y de reputación (Aslani et al., 2016; Leung y Cohen, 2011). Fosse, Ogliastri y Rendón (2017) concluyen que a pesar de pertenecer a una cultura de “dignidad" como el resto de Europa, en el contexto de las negociaciones los franceses parecen compartir muchos elementos de las culturas de "honor" como las latinoamericanas. 
En conclusión, la cultura francesa aparece con muchas contradicciones, difícil de clasificar, cuyas características no favorecen a primera vista un estilo de negociación particular. Este estudio realizado de manera holística podría integrar las variables especializadas y desconectadas de ese todo que es una cultura; $y$ de una manera inductiva se hacen inferencias que van a describir, explicar, predecir y ofrecer guías para la negociación en la cultura francesa, y dentro de ese marco se podrá apreciar la utilidad práctica de algunos de los anteriores conceptos teóricos.

\section{Metodología}

El objetivo del estudio es identificar las características negociadoras de la cultura francesa, desarrollar un entendimiento sobre sus criterios y conceptos, y llegar a predecir y desarrollar algunas prescripciones para negociar con ellos. Y para lograrlo, se utiliza una metodología cualitativa, inductiva y comparativa. La investigación se centró en preguntas de investigación (no en hipótesis, como se hace en la investigación cuantitativa).

Las cuatro preguntas centrales del estudio fueron las siguientes: ¿Cómo negocian los franceses? ¿Cuáles son las fases que siguen en su proceso negociador? ¿Por qué negocian así? ¿Qué consejos se le pueden dar a los franceses y a un latino que va a negociar con franceses?

Esos cuatro elementos constituyen una aproximación a una teoría sobre las negociaciones entre franceses y latinoamericanos, que se hace con el enfoque que integra teoría, práctica, investigación y enseñanza (Ebner y Parlamis, 2017, p. 247). El estudio se basa en entrevistas personales con preguntas semiestructuradas (ver el cuestionario en el Anexo). Todos los estudiantes de posgrado (MBA) en los cursos del primer autor (Ogliastri) realizaron una entrevista a un extranjero sobre una experiencia concreta de negociación internacional. Este era el trabajo al final de su curso de negociación, una entrevista (con su análisis), utilizando un cuestionario del profesor que había sido discutido en clase para entender los conceptos y diferencias subyacentes de las respuestas posibles. Los entrevistadores tienen la homogeneidad de conocer el tema a un nivel de práctica (ejercicios realizados en clase) y teórico (lecturas sobre conceptos de negociación, y sobre temas interculturales).

La base de datos francesa se dividió en dos categorías: A- "Extranjeros" que habían negociado con franceses. B- "Franceses", que al narrar una experiencia de negociación en 
otro país la comparaban con su propia manera de negociar. Quienes tienen experiencia internacional son principalmente un experimentado grupo de alto nivel, pero también están los inmigrantes y estudiantes (mayoría de posgrado) que desde América Latina hacia Francia suelen ser técnicos y profesionales. Un 64\% son hombres, el $95 \%$ tiene estudios universitarios, y trabajan en diversos sectores (comercio, industria, administración pública, etc.) El $54 \%$ de los entrevistados son franceses, y un $45 \%$ son ejecutivos, como puede apreciarse en las tablas 1 y 2 . Esto es una muestra de conveniencia, pero en el curso de la investigación se tomó también en consideración el concepto de "muestra teórica" al buscar la "saturación" de los datos (Glaser y Strauss, 1967), lo que implicó un número bastante extenso de entrevistas en la base de datos.

\section{Tabla 1}

Orígenes nacionales de los entrevistados (por continente)

$\mathrm{N}=244$ entrevistados

\begin{tabular}{lc}
\hline \multicolumn{1}{c}{ Continente } & Participación (\%) \\
\hline Africanos & 0,4 \\
Asiáticos & 2,0 \\
Europeos (no franceses) & 19,3 \\
Franceses & 54,1 \\
Latinoamericanos & 23,0 \\
Norteamericanos & 1,2 \\
Total general & 100,0 \\
\hline
\end{tabular}

Fuente: elaboración propia.

\section{Tabla 2}

Profesión de los entrevistados

$\mathrm{N}=244$ entrevistados

\begin{tabular}{lc}
\hline \multicolumn{1}{c}{ Profesión } & Participación (\%) \\
\hline Diplomático & 2,0 \\
Ejecutivo & 45,2 \\
Estudiante de posgrado & 14,3 \\
Estudiante de pregrado & 25,8 \\
Profesor de universidad & 7,8 \\
Otros & 4,9 \\
Total general & 100,0 \\
\hline
\end{tabular}

Fuente: elaboración propia. 
El estudio tuvo cuatro fases que fueron progresivamente validando los resultados. La primera fue un estudio exploratorio en Francia, la segunda fue una tesis de maestría, la tercera un análisis de datos recogidos por estudiantes franceses sobre una experiencia concreta de negociación. Finalmente, se consideró un grupo focal realizado por el primer autor en una universidad francesa.

En la primera etapa, Ogliastri estuvo durante dos semestres como profesor visitante en dos universidades francesas donde completó 60 entrevistas e hizo el grupo focal. La segunda etapa fue una tesis de maestría, realizada por la segunda autora (Rendón, 2004), quien realizó 51 entrevistas, mitad a franceses, durante una estancia de dos meses en París; los entrevistados se escogieron con la técnica de "bola de nieve", en la cual cada entrevistado refería a otro que podría aportar información. En el tercer estudio, también bajo la dirección del primer autor, un asistente de investigación hizo un análisis de contenido de 133 narrativas escritas de negociación (provistas por 0gliastri); estos datos fueron recogidos por estudiantes sobre una experiencia concreta de negociación, realizado sin conocer los resultados anteriores. En el cuarto estudio, el líder del proyecto conduce un grupo focal; se trata de una metodología cualitativa de investigación que se basa en la discusión en grupo, conducida mediante preguntas por un experto neutral, de un tema sobre el cual los participantes tienen información y experiencias significativas (Agar y MacDonald, 1995).

Respecto a estos cuatro estudios, el proyecto siguió los procedimientos para desarrollar una teoría basada o enraizada en datos, centrados en la comparación sistemática de datos a lo largo del proceso, la búsqueda de puntos de contradicción o enriquecimiento, y la triangulación de métodos y resultados; se empezó por el desarrollo de categorías "sustantivas", que pasarían a "formales" al profundizar en el conocimiento de la negociación francesa (Glaser y Strauss, 1967). Una parte del análisis de contenido de los resultados se realizó utilizando el software NVivo (Bazeley y Jackson, 2013).

El procedimiento fue el siguiente: 1 ) se agruparon las respuestas en frases textuales de cada pregunta en un archivo, 2) se escogieron las citas más representativas en cada tema mediante análisis cualitativo, 3) se generaron categorías integradoras ("substantivas") sobre la manera francesa de negociar, 4) se compararon los resultados de los cuatro estudios, 5) para el análisis del proceso y etapas ideales en la negociación francesa se utilizó como esquema básico el obtenido en el grupo focal realizado al final de un curso de negociación para un grupo de MBA en una universidad francesa. 


\section{Resultados: ¿Cómo negocian los franceses?}

En esta sección se presentará de forma resumida el estilo francés de negociación, originado en la cultura francesa: las costumbres, actitudes, valores, prioridades, razonamientos, expectativas y acciones o comportamiento en situaciones de diferencia de intereses o conflicto, que se consideran normales o aceptables, y suelen ser comunes y compartidos por las personas de esta región.

Según la experiencia de los entrevistados, los negociadores franceses definen claramente desde el principio lo que esperan lograr en la negociación. El marco de la negociación en esta cultura corresponde a un debate racional, en el cual se busca alcanzar los objetivos de manera ágil, rápida y eficiente a través de argumentos lógicos y sólidamente estructurados, con el fin de lograr una posición de ventaja sobre la contraparte. Como dijo un entrevistado brasileño:

Los franceses son muy cuadrados, cuadrados en el sentido de que tienen una idea predeterminada y para convencerlos de algo hay que probarlo, o sea, son muy, muy cartesianos. Que yo tengo mi modelo, mi modelo victorioso, yo gano así, entonces para yo cambiar un poco tú tienes que probarme que es tan bueno o mejor que yo, 0 que yo estoy equivocado. $(\mathrm{E}-220)^{1}$

Lo que corrobora un entrevistado francés:

Yahora los franceses creen que son más inteligentes... Pretendemos ser muy lógicos, cuando simplemente somos, usted sabe, arrogantes. (F-251)

En Francia frecuentemente se emplea el sistema de negociación tradicional, en el que una de las partes debe ceder en beneficio de la otra. Este esquema está caracterizado por el regateo a lo largo del proceso. Esta situación de "tire y afloje" es consecuencia de las aperturas extremas con que se inician las negociaciones: propuestas extremas generadas por las expectativas derivadas del acuerdo y que se encuentran asociadas al rol que desempeñan, a sus intereses o a los de la empresa que representan. Según un ejecutivo francés:

1 Todas las citas se identificarán por una F si el entrevistado es francés o E si es extranjero o no francés, y por un número con el cual se identifica en el archivo base de datos del estudio. Las citas no fueron editadas. 
Siempre hay una demanda un poquito elevada para tener un margen de negociación, ese es el tema. Y después, tienes que llegar a algo razonable, hay concesión de cada parte. Pues siempre pedimos mucho para tener poco. (F-228)

Sin embargo, el ideal racional y cartesiano de la cultura francesa lleva a muchos franceses a ser menos regateadores que otras culturas (como la latinoamericana) y en su lugar a buscar un principio general que resuelva el problema negociado. Otro ejecutivo francés resume:

Los pequeños conflictos acá (en Colombia) son negociables porque estás al frente de una persona. Allá (en Francia) no lo son porque estás al frente de una regla (F-231). Regateo... más o menos no, muy poco, porque sí, yo bajé porque, bajé de 4 millones sobre 39 millones, no es mucho; yo ya estaba como, ya bajé mi precio entonces no hubo nada más que negociar. (F-250)

En Francia se acostumbra llevar a las negociaciones un alto nivel de preparación, con datos y criterios que apoyan su máxima exigencia. Una ejecutiva colombiana que trabaja en París confirma:

Los franceses son gente que, en cierto, tiene nivel mucha formación, entonces, ellos te exigen que estés a su nivel y yo creo que por esa razón la negociación con ellos es difícil, porque tienes que estar muy informado de lo que estás haciendo, si no es así, te dejan de lado. (E-212)

La negociación se encuentra liderada por un solo vocero, quien ha sido aconsejado por el equipo que ha preparado la negociación. Un gerente general de la empresa colombiana subsidiaria de una multinacional francesa dice:

Los franceses negocian de manera jerárquica, es alguien que lleva la negociación, y luego los demás tienen que hacer lo que se les dice, y la clave del éxito está ahí. Y luego, sí, manejan la cosa de manera metódica. (E-230)

Esta apreciación la confirma un argentino en París:

Hasta que intervino alguien con más jerarquía del servicio y calmó un poco la cosa... Finalmente cambió a la persona que estaba a cargo del trámite. (E-221) 
La cultura francesa se caracteriza por el cuidadoso protocolo, la formalidad en los acuerdos, el cumplimiento de la agenda y la claridad en los compromisos pactados. Varias opiniones de negociadores extranjeros ilustran este punto.

Vuelvo sobre esa cuestión del lenguaje diplomático, del lenguaje que, no sé bien como decirte, pero que supone como saber muy bien cuáles son las cosas que están implícitas (E-206). Yo sentí mucha agresividad. Uno sabe acá que uno es extranjero, pero ella me lo hacía sentir de una manera muy discreta, muy discreta y muy agresiva. Son más reservados en sus sentimientos, en la expresión de sus sentimientos, que no te van a decir necesariamente de una vez lo que no les gusta... con los conflictos... Se cuidan mucho de mostrarse tal como son. (E-204)

Finalmente, en el momento de la negociación, también aparecen las emociones, donde la parte francesa se muestra fuerte e impositiva sobre su lógica y razonamiento. Dos ingenieros colombianos que trabajan en París comentan:

Los franceses creen siempre que tienen la razón. No hay manera de discutir lo que ellos piensan, que es así, son un poco cuadrados o "carrés", que es el término que ellos utilizan. Siempre creía que él tenía la razón... Si usted se adapta, bien, y si no... ¡también!... es un poco duro (E-222). Los franceses son negociadores duros. (E-202)

En síntesis, la pregunta de investigación sobre cómo se negocia en Francia se puede resumir de la siguiente manera: el estilo de negociación predominante en Francia es racional, se orienta hacia la consecución efectiva de objetivos, al uso de la confrontación y el debate lógico para lograr una posición de ventaja sobre la contraparte. Altamente competitiva y desconfiada, esta cultura tiende a entender la negociación como una situación donde se gana o se pierde y frecuentemente se cree que las ganancias del uno son pérdidas del otro ("suma cero" en teoría de juegos). Es una cultura formal y protocolaria, lo que enmarca o contiene la expresión a veces muy fuerte de emociones. Las aperturas extremas y cuidadosamente justificadas, inducen un proceso lento de regateo en el cual amenazas y desplantes se mezclan con encanto (charme), para presionar al otro. Aunque se apoye en las recomendaciones del equipo, la negociación es realizada por el jefe jerárquico, de quien se espera tome pocos riesgos, maneje ordenadamente el tiempo y proceda a dejar por escrito los acuerdos. Se encontraron diferencias entre las negociaciones empresariales o políticas con el manejo de conflictos personales; las primeras tienen un carácter más profesional y lógico, en las segundas predominan las emociones fuertes. 


\section{¿Cuál es la secuencia ideal de acciones y por qué negocian así los franceses?}

En esta sección presentamos los resultados del grupo focal y pasamos a interpretar y explicar las razones por las cuales se dan estos comportamientos de negociación en la cultura francesa. El grupo focal fue realizado con la participación de 18 estudiantes de MBA franceses (15) y españoles (3) que habían hecho entrevistas de investigación sobre las experiencias de un extranjero en Francia y las de un francés en otro país. Se concluyó que la cultura francesa de negociación se caracteriza porque las decisiones las toma la más alta jerarquía, se recurre a la discusión lógica y a la precisión verbal, se experimentan confrontaciones y conflictos abiertamente, la información está fraccionada en las instituciones y, por último, es muy importante el protocolo: formalidad personal, seguir las reglas, dejar todo por escrito, hacer eventos de relaciones públicas. Estos resultados validan los datos de las entrevistas, y adicionalmente se enfocó una pregunta y análisis en grupo sobre el proceso "ideal” francés para conducir una negociación. A continuación, presentamos los pasos considerados ideales y deseables en el proceso de negociación de la cultura francesa, y aportaremos explicaciones para entenderla.

En primer lugar, en la cultura francesa se prefiere una cuidadosa preparación de los temas de la negociación. Esto implica por lo general un trabajo de los niveles subalternos, que recomiendan aljefe parámetros para la negociación, que él (o ella) pueden seguir o no seguir según se desarrolle el proceso. También algunos entrevistados mencionaron: "No quiero ir a la negociación con vacios" (F-228).

Las interpretaciones sobre las razones para explicar y entender este comportamiento pueden tener dos vertientes. Una explicación se basa en antecedentes históricos y valores culturales. El otro tipo de causas del comportamiento es el efecto que quieren obtener de su contraparte en la negociación. En este punto, como origen interpretamos que se preparan cuidadosamente para evitar incertidumbres, un valor importante en la cultura francesa (Hofstede, 2016); como propósito se entiende o justifica por no querer tener problemas y "vacíos" en el proceso posterior.

Segundo, en la cultura francesa se considera ideal llevar a la negociación formal los objetivos que quieren alcanzar, que sean mensurables y sustentados en razones técnicas, en criterios objetivos o en principios y leyes generales, a través de los cuales se 
resuelva el problema global o el conflicto de la negociación. Esta observación del grupo focal también apareció en las entrevistas:

La claridad sobre los objetivos últimos de negociación y la voluntad de las dos partes de conseguirlo y en un plazo dado. Quizás antes de empezar a negociar (F-229). De manera muy objetiva plantean lo que ellos quieren, son muy claros, no pierden tiempo en rodeos en las ideas. Son muy objetivos, van directamente al grano. (E-224)

La explicación de este comportamiento es el cartesianismo, el racionalismo como un valor histórico muy fuerte en la cultura francesa. Su racionalismo no es el de costos y beneficios (como en la cultura anglosajona) sino principios generales. Como explicara uno de los entrevistados franceses:

¡Descartes es Francia!... a usted lo entrenan así cuando va a la escuela de niño. Las tareas de clase deben tener una organización de forma lógica, paso a paso, lo que forma su mente. (F-251)

(En Francia) Estás al frente de una administración, de una empresa. Acá (en Colombia) no, acá estas frente de la gente. (E-231)

Tercero, las actitudes y posturas que se llevan a la negociación y aparecen desde el primer encuentro: la imagen que se quiere proyectar, y los criterios que se quieren establecer para el proceso posterior. En Francia se considera mejor parecer fuerte, rápido, inteligente, con superioridad intelectual personal y de la empresa o del país; de manera tácita se muestra el poder relativo de las partes (como cuál es el país o empresa más desarrollada, cómo es la jerarquía en la mesa, la superioridad de costumbres y formas...). Adicionalmente en Francia se considera "profesional" separar el negocio de lo personal, el énfasis en números, esperan establecer reglas de juego que limiten el conflicto, y tienen una actitud presionada del tiempo. Esto aparece evidente para los otros al comenzar, la posición de fuerza francesa, el comportamiento de debate y discusión sin mucho interés por la relación personal, que interpretan las otras partes como arrogancia sin reparar en humillación, la imposición de sus criterios sin escuchar al otro (incluida aquí la poca relación personal). También sobre este punto tenemos aportes franceses de las entrevistas:

Creemos que nuestro sistema es el mejor... Estado de bienestar... Sistema democrático... La policía puede hacer lo que en otras partes no se puede... Usted crece con 
la idea de que tiene filosóficamente la más avanzada cultura del mundo... y el más avanzado sistema político de Europa. (F-237)

[Francia] tuvo un pasado muy glorioso y también... colonialista, así que hubo muchísima experiencia de ir a explicar a los demás que los franceses son superiores, y eso se quedó un poco en la cultura del país. (F-242)

Los franceses quieren ser percibidos como inteligentes, rápidos... el sentimiento de que un buen negociador es un negociador rápido... es diferente con respecto a otras culturas... aquí es muy fuerte (F-251)

No gastamos tiempo en preguntar cómo está la familia y que tal se encuentran en Costa Rica o en Francia, y cosas así. Creo que es mucho más directo. Sabemos por qué estamos aquí... en Francia no es tan necesario entablar una relación personal con la persona con quien estamos negociando. Es más formal. (F-240)

Para mí, que tuviéramos una amistad o no era completamente irrelevante; que él sea amable o no era completamente irrelevante. Lo que era relevante era mi posición, estoy aquí para pedirle una pasantía/práctica. Él es jefe, él es la persona que me contratará. Y ese marco estaba muy bien arraigado en mi mente. (F-237)

Como observan dos colombianos:

Francia es una potencia y a nivel cultural tuvieron un nivel muy alto, se muestran fuertes (E-222). No hacen tanto preludio para conocer a la otra persona, no les interesa. $(\mathrm{E}-224)$

El ideal de lo racional lleva a dejar de lado las emociones (propias) y las relaciones interpersonales, para enfatizar números; esto también es evidente en el comienzo de la negociación.

La mejor manera de negociar para nosotros los franceses es... llevar cifras, la gente no acepta que usted tenga una opinión diferente a no ser que se lo pueda probar con números (F-243). Siempre ponen primero sus argumentos, justifican bastante lo que piensan, siempre tienen puntos de vista fuertes. (E-218) 
La explicación para estos comportamientos en la cultura francesa de negociación puede encontrarse en que los franceses encuentran ideal un alto grado de asertividad, aún mayor del que ya tienen superior al promedio mundial (Chhokar et al., 2007); este comportamiento duro y afirmativo no solo es tolerado sino considerado ideal. El debate, la discusión abierta y retórica han sido promovidos desde la escuela y explica en gran parte esta actitud que sorprende a otras culturas. Otra razón de tipo cultural es que se aceptan como normales las diferencias de poder y jerárquicas (Hofstede, 2003), que tienen así un impacto en la manera de negociar. Posiblemente este comportamiento sea eficaz (aunque resentido) en otras culturas como las latinoamericanas que también tienen alta distancia de poder.

Cuarto, en el proceso de negociar se generan muchas más variaciones que en los apartados anteriores. No hay una actitud prevalente ideal homogénea. En Francia parecen coexistir los dos prototipos de negociador que contempla la literatura. La mayoría de los franceses consideran conveniente plantear una demanda y beneficios altos (para bajar después), lo que implica los criterios técnicos se esbozan retóricamente de tal forma que les favorezca totalmente. Este planteamiento es así una forma de regateo, sustentado por razones técnicas y objetivas (a diferencia del regateo como una sonda exploratoria sin muchas bases para ver la reacción del otro, lo que es una manera más rústica de operar). En la cultura francesa se utilizan técnicas sofisticadas de regateo, pero no es interminable como en el Medio Oriente: “Tú haces una proposición comercial, haces una segunda proposición, y máximo una tercera, y ya. Si no se hace a la tercera, no se hace" (F-227).

Un entrevistado planteó lo aprendido en una clase de negociación en una reconocida universidad francesa:

El proceso es como los cambios o marchas de un automóvil. Se arranca en primera: una propuesta exigente y durísima que ni en sueños usted podría alcanzar (pero la presenta para que el otro la adopte como primera referencia y se sienta ganador al final). Después se pone el segundo cambio: un posible acuerdo que al otro le convendría, pero que usted lo presenta como ridículo e imposible, para que el otro tenga que mejorarlo bastante. Después viene la tercera: aquella muy favorable para usted (a la que realmente aspira) pero la presenta como una solución intermedia que no le atrae demasiado. Finalmente pone la cuarta: una propuesta que le gustaría mucho pero que sabe es muy difícil de alcanzar, y la presenta como su propuesta final, 
contemporizadora, intermedia, razonable, bien argumentada. Se hacen muy pocas e ínfimas concesiones, y sólo al final, cuando no haya mucha esperanza de acuerdo y se haya acabado el tiempo; entonces se acepta, de aparente mala gana, la tercera propuesta. (E-5)

No obstante, este procedimiento no parece universal en el comportamiento francés:

Eso de siempre negociar, de siempre regatear... es una cosa que nunca se da en Francia... Los pequeños conflictos acá (Colombia) son negociables porque estás al frente de una persona. Allá no lo son porque estás al frente de una regla... pero es un juego en buscar límites y una vez que los dos los han encontrado está bien. (F-231)

En Latinoamérica no se basan tanto en las leyes como los franceses, o en la historia de las soluciones. (F-245)

El proceso tiene mucho de persuasión retórica, se tiene una fuerte inclinación de convencer a la contraparte y en menor grado a entrar en la dinámica de negociación de compartir intereses y hacer concesiones que lleven a un acuerdo beneficioso para ambos. Este enfoque puede llevar a los negociadores franceses a olvidar la condición humana de su contraparte y a ser percibidos como negociadores duros, arrogantes y cerrados en sus posiciones. Igualmente, su afán los puede llevar a abandonar la mesa de negociación antes de tiempo, sin haber explorado suficientemente intereses y alternativas y por consiguiente pueden dejar valor sobre la mesa de negociación (Malhotra y Bazerman, 2008).

Esta diferencia de enfoques se explica por la existencia de los dos tipos de negociación en la cultura francesa. De un lado está la creencia, que en teoría matemática de juegos se llama "suma cero" (la ganancia de una parte implica la pérdida del otro, ganar/perder) lo que no permite buscar beneficios mutuos. En esto influye la educación: los estudiantes franceses lo contrastan abiertamente al final del curso de negociación, cuando han aprendido nuevas técnicas que permiten creación de valor mutuo, el gana-gana que les permite alcanzar mejores resultados que el sistema tradicional. Tras conocer el nuevo enfoque, ellos analizan críticamente a esa mayoría que persiste en una metodología de regateo tradicional.

Quinto, en el proceso de la negociación se acostumbra separar instancias formales e informales, y no mezclar actividades sociales con la negociación. La explicación para 
este comportamiento es que en su ideal racionalista, no se considera muy elegante el transigir por fuera de la mesa de negociación (Damasio, 1994; Glucksmann, 1987). Las cenas son para hablar de otras cosas, como de aficiones, vacaciones, cultura, para disfrutar, no para el duro trabajo de la negociación. Pero puede darse al final una cena que cierre el proceso.

Otro elemento importante que intentan desarrollar a lo largo del proceso son reglas de formalidad y cortesía. Una razón para este comportamiento es el espíritu deductivo de la cultura francesa, tal como es su sistema legal (códigos napoleónicos basados en los romanos) en lugar de construir inductivamente la ley, caso por caso, como hacen los anglosajones. Otra razón es su propósito de regular los conflictos y su desarrollo dentro de cauces racionales, de profesionalismo y respeto. Según un colombiano que prepara un doctorado en París:

Yo pienso que las reglas de formalidad y de diplomacia, etc., son reglas importantes en cuanto a que ellas ayudan a contener algo que a veces puede hacer desbordar los conflictos... infringí un punto, una norma que culturalmente debí haber respetado, y que era la norma de la politesse. (E-206)

Sexto, en la cultura francesa se tiene una clara preferencia por acuerdos escritos, con mucha precisión del idioma, y sin mucho espacio para cambios posteriores. "Ser muy claro, escribirlo todo, ser cuidadoso con lo dicho verbalmente" (F-236). Este comportamiento se explica por el bajo contexto comunicativo, los franceses valoran la precisión del idioma y buscan acuerdos escritos que eviten ambigüedades (Hall y Hall, 1990). Esto se aúna con el deseo de evitar incertidumbres (Hofstede, 2003).

Nuestra interpretación se basa, en gran parte, en los valores culturales franceses, entendiendo la negociación como una cultura, como un comportamiento aprendido en el hogar, en la escuela, y en la vida en general. Esencialmente la cultura francesa tiene una concepción racional que se explica por los orígenes históricos del racionalismo francés, que se ha propagado y mantenido en la cultura a través del sistema educativo (las escuelas públicas), donde el debate y confrontación intelectual se cultiva en los estudiantes (Azouvi, 1998). Es también considerado “normal” como nos han dicho los entrevistados franceses, que se busquen reglas racionales, criterios objetivos, para resolver los temas y puntos en discusión. La cultura formal y protocolaria apoya que la negociación no se salga de cauce, limita el conflicto, evita ofensas, y así ayuda a resolverlo. La cultura 
francesa tiene algo de "honor" y algo de "dignidad", lo que explica comportamientos negociadores contradictorios de agresión y encanto (Fosse et al., 2017).

Hemos descrito, interpretado y explicado el estilo francés de negociación, basados en el estudio de enfoque y en las observaciones tanto de extranjeros como nacionales. El paso siguiente es generar recomendaciones para negociar con la cultura francesa.

\section{Las experiencias y recomendaciones de los extranjeros}

En esta parte se presentan algunas observaciones de los extranjeros sobre lo que les molestó de negociar con franceses, lo que les resultó más sorprendente y las recomendaciones que darían a quienes vayan a negociar con franceses. Se analizarán los resultados obtenidos como respuesta a estas preguntas: ¿Qué le molesta a su contrapartida del estilo de negociación más común en Francia? ¿Qué es lo que más les sorprende al negociar con franceses? ¿Qué consejos le darían a alguien que vaya a negociar en Francia? Finalmente se presentará a manera de síntesis en la tabla 3 un resumen de los hallazgos y conclusiones obtenidos en las entrevistas.

¿Qué molesta a los extranjeros (no-franceses) de sus experiencias de negociación con franceses?

En algunas culturas, como la latinoamericana, pueden sentirse agredidos ante la franqueza y confrontación en los intercambios de las negociaciones, que encuentran antipática e interpretan como arrogancia, como exceso de orgullo, de egocentrismo y demasiado agresiva, a pesar de estar arropada por la formalidad. Varias opiniones de negociadores extranjeros ilustran este punto. Un gerente general colombiano afirma:

La arrogancia, ellos son arrogantes, ¿en qué sentido? Sienten y piensan que tienen la verdad revelada, tienen un ego gigante y manejar esos egos no es fácil. Además, como ellos representan a empresas poderosas... sienten que tienen privilegios simplemente por ser miembros de esa empresa. (E-202)

En lo que coincide un estudiante español:

Tuvimos un pequeño lío, un pequeño follón en el hotel las dos primeras noches con el recepcionista, que era un típico francés antipático y grosero. Es decir, como la 
mayoría de los franceses, sobre todo... bueno sobre todo cuando se trata de españoles... (E-152)

Un estudiante argentino que hace su doctorado en París describe así sus experiencias con franceses:

El maltrato es más sutil, te contestan mal, no te miran cuando te hablan, pero es raro que te griten... una característica común es que alguien te repita varias veces lo que le dices porque supuestamente no entiende, y en realidad te repite para mostrar cual es la buena pronunciación en francés de lo que uno dice. (E-221)

Los diálogos en francés entre ellos son parte de una impresión de irrespeto que a veces se lleva la contraparte. Por ejemplo, un diplomático venezolano comenta:

Durante las reuniones de negociación mantuvieron respeto al derecho de palabra de sus colegas, aunque en ocasiones también establecían diálogos en su idioma, aspecto que no agradaba a la parte venezolana... Dan la impresión de que no tienen respeto por el interlocutor. Fue lo único que no me gustó de esa negociación. (E-154)

Otro malestar expresado por algunos entrevistados es haberse sentido manipulados, una falta de transparencia que a veces los hizo sentirse engañados. Dos estudiantes doctorales afirman:

Me desconcertó que no sentí de su parte mucha transparencia y sobre todo cómo ser directa en un momento dado, en comunicarme lo que ella estaba pensando, porque había mucha ambigüedad. (E-206)

Las estudiantes francesas con las que he compartido piso en Roma, por ejemplo, también eran algo distantes y parecía que, en ciertas ocasiones, se “guardaban ases bajo la manga". (E-162)

\section{¿Qué le sorprende a la gente de negociar con ellos?}

Un grupo de entrevistados extranjeros se sorprende de que los franceses actúen de manera muy individualista y no se incomoden ante situaciones de conflicto, como podría suceder con culturas orientadas a las relaciones interpersonales como la latinoamericana. Sin embargo, pueden llegar a manejar un lenguaje subliminal y sutil difícil de comprender 
para otras culturas. De sus consultas con varios pacientes, una doctora colombiana que trabaja en París concluye:

Ellos usan mucho el lenguaje verbal, además porque el francés yo pienso que es un idioma que se presta mucho a eso. La construcción idiomática... hace que tú puedas ser muy sutil... eso hace que a veces... tu no sepas realmente lo que ellos te están diciendo. 0 sea, que no te están diciendo no, pero tampoco te están diciendo sí. (E-204)

Sorprenden los cambios de estado de ánimo y lo temperamentales que pueden ser los negociadores franceses. Por ejemplo, un político y profesor latinoamericano dice:

Me sorprenden los fuertes cambios que tienen durante el proceso, ofrecen una relación amistosa y de beneficio mutuo, cuando ven que la otra parte la acepta, la intimidan para que acepte sus altas condiciones, y así continuamente. ...A mí me ha dado la sensación de que los franceses cuando negocian piensan que están jugando a un juego o representando una obra de teatro en la que han escrito el guión, y en la que ellos deben ser los actores principales, los que se lucen y finalmente ganan. (E-275)

La seriedad y susceptibilidad con que se toman las cosas, los conflictos como algo normal en las relaciones y la vida en general, llevan a algunos a concluir que en Francia se atormentan demasiado, que toman las cosas demasiado en serio y se ofenden con gran facilidad. Dice un estudiante mexicano que lleva siete años viviendo en París:

Sobre un problemita que tú lo puedes resolver haciendo una broma simplemente... ellos (los franceses) realmente lo quieren resolver ya sea invitándote a cenar para hablar seriamente sobre el problema en cuestión o incluso dejándote de hablar porque han sido muy afectados. (E-209)

A culturas más extrovertidas como la latinoamericana, les sorprende la distancia personal común en Francia. Algunos se sorprenden por el trato que normalmente dan a sus clientes los vendedores en una tienda en Francia: Una estudiante canadiense de Quebec dice:

Los franceses tienen una manera más fría de acercarse a las personas y se refleja en su manera de negociar. Para los franceses la historia de su país es mucho más importante que en nuestra sociedad. Pero la diferencia más grande es que entre nosotros el cliente tiene la razón, y no el vendedor como en Francia. (E-117) 
El ejecutivo salvadoreño de una empresa aérea que tiene un conflicto con un proveedor francés describe:

En mi experiencia profesional he comprobado que existe cierto patrón cultural que hace a los franceses muy displicentes y despreciativos hacia personas o profesionales que a lo mejor consideran inferiores. (E-171)

Finalmente, algunos se sorprenden por la necesidad de tener un buen nivel cultural para tratarlos, puesto que son personas muy cultas y comunicativas. Por ejemplo, según este ejecutivo alemán que vende productos de un banco:

Se necesita mucha cultura para ir a negociar con un francés. ¡Yo conozco a ejecutivos a quienes daban clases de cultura general precisamente para ir a negociar con franceses! (E-108)

\section{¿Qué consejos le da a alguien que va a negociar con franceses?}

El primer consejo de los negociadores extranjeros que han tenido contacto con la cultura francesa de negociación, es estar muy preparado para el proceso de negociación, tener argumentos sólidos, cifras e ir directamente al grano. Un ejecutivo colombiano que trabaja en París sugiere:

Que tenga las cosas muy claras, donde va a intervenir, donde va a negociar... que conozca mucho el mercado donde va y así no va a tener ningún problema. Cuando ellos ven que la persona conoce, que tiene un cierto conocimiento, que van preparados sobre lo que negocian, no hay problemas. (E-219)

Lo que corroboran tres visiones externas de la cultura francesa (extranjeros), un diplomático venezolano y dos españoles:

Preparar bien sus propuestas antes de sentarse a negociar. Conocer bien los intereses de la contraparte. (E-154)

Le aconsejaría que preparase bien la negociación que va a llevar a cabo y los argumentos que va a presentar en la mesa de negociación. (E-163) 
Primero que todo, tener claros los objetivos. En las tres primeras frases tiene que decir lo que quiere, limpio y transparente, que sean frases muy bien construidas, muy organizadas. A partir de ahí se puede elaborar por horas... (E-152)

Se recomienda conocer la cultura francesa y su forma de negociar. Un ejecutivo español comenta, con respecto a su negociación en Francia:

Hay que tener clara la diferencia entre el savoir, el savoir-faire y el savoir-être. Para un ingeniero español el savoir, es decir, los conocimientos técnicos, son muy importantes, mientras que para un francés lo que cuenta es el savoir-faire, es decir, el saber hacer las cosas, dejando en segundo término los conocimientos técnicos (savoir)... Asimismo, resaltar la importancia del savoir-être, es decir, el saber ser de aquellos al respecto de la intimidad y la alta formalidad y educación que deben mostrar en el ámbito profesional y que es la principal diferencia en esa cultura. (E-155)

Un estudiante español propone, a partir del conflicto personal en un contexto de deporte:

Que sea lo más abierto posible, no ofender en ningún momento a la otra parte (menosprecio hacia lo francés, por ejemplo), razonar su postura e intentar hacer ver que no es la única posible (ofreciendo alternativas), y sobre todo no ofenderse ante su actitud poco cercana y tajante. (E-165)

Otro consejo de nuestros entrevistados es ser paciente con los franceses y tener un acercamiento gradual, ya que pueden sentirse rápidamente invadidos en su propia esfera. Por ejemplo, un colombiano que vive en París desde hace tres años recomienda:

No dejarse intimidar por las actitudes que puedan manifestarse durante la negociación, ni tomarse las cosas personalmente o sentirse necesariamente agredido. Hablar, decir las cosas. A lo mejor enfrentarse, tener un conflicto y no dejar las cosas tapadas (E-242). Ser calmado y acostumbrarse a lo que hay aquí. (E-158)

Dos estudiantes españoles aconsejan:

También le diría que no se deje intimidar por una aparente frialdad y que hiciese preguntas abiertas para obtener el máximo de información de su interlocutor. (E-163) 
En mi opinión, la mejor forma de neutralizar su táctica, es no entrar en su juego y mostrar indiferencia, entonces rebajan considerablemente la presión. (E-167)

Otro consejo reiterado es el tener dominio del idioma francés, porque a veces parecen muy etnocéntricos. Un ejecutivo colombiano que ha vivido en París durante los pasados ocho años recomienda:

Conocer a fondo, hablar su lengua, el francés. Son muy reacios a las lenguas extranjeras, sobre todo a las que no son latinas. (E-222)

El investigador argentino que estudia en París recomienda:

Primero que aprenda bien francés... Una especie de situación de poder en la que se plantan y es súper inamovible. Es difícil que ellos acepten establecer códigos comunes que no sean o que impliquen moverse del uso del francés, por ejemplo. (E-221)

Ser flexible para comprender la cultura francesa, y estar preparado para el cambio de mentalidad. Dice una médica pediatra de Bogotá que trabaja en un hospital francés:

Le advertiría que la manera de ver las cosas no es la misma, que la mejor manera de hacerse entender, no diría hacerse respetar porque es una palabra un poco fuerte, pero para hacerse entender de un francés es necesario demostrar que también se puede llegar a un resultado utilizando otros métodos. (E-205)

Mantener las buenas maneras, la formalidad, es importante. Un brasileño que trabaja como empleado en un hotel en París comenta:

El formalismo es esencial... Son unos cinco minutos de introducción, de buenos días... Hay que esforzarse en hacer formalismos; así te van a tratar mucho más abiertos, como si fueras un francés... tengo un formalismo que es un poco francés, como abrir la puerta... Esos formalismos ayudan a mantener un clima cordial... (E-215)

\section{Síntesis y conclusiones}

Se han presentado análisis de experiencias concretas de negociación entre franceses y extranjeros (especialmente latinoamericanos y españoles). Aunque estudios previos habían analizado el estilo francés de negociación, enfocados en una perspectiva cuan- 
titativa (Adair et al., 2004; Brett et al., 1998) en este artículo proponemos un análisis inductivo, comparativo, estructurado y cualitativo del estilo francés de negociación.

Este artículo ha integrado cuatro estudios sobre la cultura francesa de negociación, y se inscribe dentro de un extenso proyecto de investigación sobre negociación intercultural (0gliastri, 2000). A manera de síntesis y conclusiones, en la tabla 3 agrupamos los resultados de los tres estudios con entrevistas, y se presenta una interpretación integradora. Las 20 categorías de análisis se generaron a partir de las 12 variables para negociación intercultural presentadas originalmente por Weiss y Stripp (1985), desarrollo hecho con métodos comparativos entre diferentes culturas de negociación; primero se amplió a 17 categorías (0gliastri, 2002) y más adelante a 20 categorías por la comparación entre la cultura holandesa de negociación y la colombiana (Van Hoof, Ogliastri, Bernal y García, 2005). La conclusión más general es que hay una cierta consistencia entre los resultados de las entrevistas, lo que permitió un resumen integrando los resultados. Los datos son también consistentes con el grupo focal, lo que implica una validación adicional, también por "triangulación" (Patton, 2002) de los resultados obtenidos con diferentes métodos.

\section{Tabla 3}

Integración de resultados sobre el estilo de negociación en Francia

\begin{tabular}{|c|c|c|c|c|c|}
\hline & Categoría/Estudio & Estudio 1 & Estudio 2 & Estudio 3 & Integración \\
\hline 1 & $\begin{array}{l}\text { Entendimiento } \\
\text { de la negociación }\end{array}$ & $\begin{array}{l}\text { Debatir, } \\
\text { confrontar }\end{array}$ & $\begin{array}{l}\text { Argumentar, } \\
\text { contra argumentar, } \\
\text { agilidad, rapidez }\end{array}$ & $\begin{array}{l}\text { Sistema tradicional. } \\
\text { Regateo durante } \\
\text { el desarrollo del } \\
\text { proceso. }\end{array}$ & $\begin{array}{l}\text { Debate racional } \\
\text { Con regateo }\end{array}$ \\
\hline 2 & $\begin{array}{l}\text { Concepción de la } \\
\text { contraparte }\end{array}$ & Contrincante & $\begin{array}{l}\text { Alguien a quien } \\
\text { se debe afrontar, } \\
\text { convencer }\end{array}$ & $\begin{array}{l}\text { Neutro o amigo } \\
\text { en negociaciones } \\
\text { corporativas por } \\
\text { intereses comunes. } \\
\text { Adversario en } \\
\text { conflictos de } \\
\text { intereses. }\end{array}$ & $\begin{array}{l}\text { Alguien a quien } \\
\text { convencer, } \\
\text { profesionalmente; } \\
\text { o adversario en } \\
\text { conflictos personales }\end{array}$ \\
\hline 3 & $\begin{array}{l}\text { Perspectiva } \\
\text { temporal }\end{array}$ & Mediano & Largo plazo & $\begin{array}{l}\text { Largo plazo en } \\
\text { negocios, busca } \\
\text { intereses comunes. } \\
\text { Corto plazo, sin } \\
\text { futuro en conflictos } \\
\text { de intereses. }\end{array}$ & $\begin{array}{l}\text { Mediano y largo } \\
\text { plazo, rápidos }\end{array}$ \\
\hline 4 & $\begin{array}{l}\text { Base de la } \\
\text { confianza }\end{array}$ & $\begin{array}{l}\text { Lenta, según } \\
\text { hechos }\end{array}$ & $\begin{array}{l}\text { Roles, lenta, } \\
\text { reglamentación } \\
\text { implícita }\end{array}$ & Desconfiados & $\begin{array}{l}\text { Desconfiados hasta } \\
\text { que se demuestre lo } \\
\text { contrario }\end{array}$ \\
\hline
\end{tabular}




\begin{tabular}{|c|c|c|c|c|c|}
\hline & Categoría/Estudio & Estudio 1 & Estudio 2 & Estudio 3 & Integración \\
\hline 5 & Toma de riesgos & Conservador & $\begin{array}{l}\text { Riesgos calculados, } \\
\text { precavidos, aversión }\end{array}$ & Conservadores & $\begin{array}{l}\text { Conservador, } \\
\text { aversión al riesgo, } \\
\text { precavidos, calculan }\end{array}$ \\
\hline 6 & $\begin{array}{l}\text { Quienes } \\
\text { negocian }\end{array}$ & Jefe solo & Rango mayor, solo & $\begin{array}{l}\text { Nivel directivo o } \\
\text { personal capacitado }\end{array}$ & El jefe \\
\hline 7 & $\begin{array}{l}\text { Toma de } \\
\text { decisiones }\end{array}$ & $\begin{array}{l}\text { Individual, } \\
\text { centralizada }\end{array}$ & $\begin{array}{l}\text { Discusión grupal, } \\
\text { decisión por consen- } \\
\text { so o individual }\end{array}$ & $\begin{array}{l}\text { Los mismos que } \\
\text { negocian }\end{array}$ & $\begin{array}{l}\text { Equipo prepara, reco- } \\
\text { mienda, el jefe decide } \\
\text { en la negociación }\end{array}$ \\
\hline 8 & Formalidad & $\begin{array}{l}\text { Buenas } \\
\text { maneras }\end{array}$ & $\begin{array}{l}\text { Alta, jerárquica, } \\
\text { buen trato }\end{array}$ & $\begin{array}{l}\text { Cuidadoso de las } \\
\text { buenas formas, } \\
\text { protocolarios. }\end{array}$ & $\begin{array}{l}\text { Protocolo, buenas } \\
\text { maneras, importa la } \\
\text { jerarquía. }\end{array}$ \\
\hline 9 & $\begin{array}{l}\text { Negociaciones } \\
\text { informales }\end{array}$ & Poco común & $\begin{array}{l}\text { Frecuentes, contacto } \\
\text { formal }\end{array}$ & $\begin{array}{l}\text { Limitadas al acerca- } \\
\text { miento de las partes o } \\
\text { al cierre del proceso. }\end{array}$ & $\begin{array}{l}\text { En las reuniones } \\
\text { informales no se } \\
\text { negocia. }\end{array}$ \\
\hline 10 & Prenegociaciones & Poco común & $\begin{array}{l}\text { Inusual, preparación } \\
\text { metódica }\end{array}$ & Eventuales & Poco comunes \\
\hline 11 & Apertura & $\begin{array}{l}\text { Alta con } \\
\text { argumentos }\end{array}$ & $\begin{array}{l}\text { Alta-mediana, basada } \\
\text { en criterios objetivos }\end{array}$ & $\begin{array}{l}\text { Extremas según } \\
\text { posición }\end{array}$ & $\begin{array}{l}\text { Petición extrema } \\
\text { fundamentada }\end{array}$ \\
\hline 12 & Argumentación & $\begin{array}{l}\text { Retórica, } \\
\text { discusión }\end{array}$ & $\begin{array}{l}\text { Discusión } \\
\text { estructurada, } \\
\text { convencer }\end{array}$ & Debate & $\begin{array}{l}\text { Discutir, usar } \\
\text { criterios objetivos, } \\
\text { lógica deductiva. }\end{array}$ \\
\hline 13 & Emocionalidad & $\begin{array}{l}\text { Alta, } \\
\text { convencer }\end{array}$ & $\begin{array}{l}\text { Racionalizada, } \\
\text { contenida, } \\
\text { manipular }\end{array}$ & Temperamentales & $\begin{array}{l}\text { Aceptable expresión } \\
\text { emociones, instru- } \\
\text { mento negociación. }\end{array}$ \\
\hline 14 & Tácticas de poder & $\begin{array}{l}\text { Contestación } \\
\text { abierta }\end{array}$ & $\begin{array}{l}\text { Amenazar, } \\
\text { confrontar, hacer } \\
\text { teatro }\end{array}$ & $\begin{array}{l}\text { Presión sobre el otro } \\
\text { según la posición } \\
\text { que asuman }\end{array}$ & $\begin{array}{l}\text { Confrontar, presionar, } \\
\text { uso del poder es } \\
\text { normal }\end{array}$ \\
\hline 15 & $\begin{array}{l}\text { Nivel de } \\
\text { discusión }\end{array}$ & $\begin{array}{l}\text { Preciso, no } \\
\text { concreto }\end{array}$ & $\begin{array}{l}\text { Datos enmarcados } \\
\text { en principios, no } \\
\text { concretos }\end{array}$ & No concretos & $\begin{array}{l}\text { Precisión verbal, } \\
\text { principios generales, } \\
\text { deductivos. }\end{array}$ \\
\hline 16 & $\begin{array}{l}\text { Tiempo en la } \\
\text { negociación }\end{array}$ & $\begin{array}{l}\text { Puntuales, } \\
\text { segmentados }\end{array}$ & $\begin{array}{l}\text { Mono crónicos, pun- } \\
\text { tuales, ideal rapidez }\end{array}$ & $\begin{array}{l}\text { Avanzan punto a } \\
\text { punto de la agenda }\end{array}$ & $\begin{array}{l}\text { Puntualidad es ideal, } \\
\text { segmentan agenda. }\end{array}$ \\
\hline 17 & Tipo de acuerdo & $\begin{array}{l}\text { Escritos, } \\
\text { detallados }\end{array}$ & $\begin{array}{l}\text { Escrito, poca } \\
\text { formalidad jurídica }\end{array}$ & $\begin{array}{l}\text { Escritos en acuerdos } \\
\text { de carácter formal }\end{array}$ & $\begin{array}{l}\text { Prefieren escrito, } \\
\text { detallado. }\end{array}$ \\
\hline 18 & $\begin{array}{l}\text { Cumplimiento y } \\
\text { compromiso }\end{array}$ & No datos & Cumplidos, rigurosos & $\begin{array}{l}\text { Estricto y compro- } \\
\text { metido; pero no } \\
\text { siempre es cumplido. }\end{array}$ & Cumplidos \\
\hline 19 & Flexibilidad & No datos & $\begin{array}{l}\text { Cerrados, } \\
\text { inflexibles, se basan } \\
\text { en principios }\end{array}$ & $\begin{array}{l}\text { Asociada a intereses } \\
\text { propios y al desarro- } \\
\text { llo del proceso }\end{array}$ & $\begin{array}{l}\text { Esperan cumplimien- } \\
\text { to del principio y del } \\
\text { acuerdo. }\end{array}$ \\
\hline 20 & $\begin{array}{l}\text { Forma de } \\
\text { expresarse }\end{array}$ & No datos & $\begin{array}{l}\text { Directa, franca, } \\
\text { calculada }\end{array}$ & $\begin{array}{l}\text { Fácil comunicación, } \\
\text { pero sin claridad. } \\
\text { Rodeos en el manejo } \\
\text { de la información. }\end{array}$ & Expresivos, verbales \\
\hline
\end{tabular}

Fuente: elaboración de los autores. 
En el estilo francés de negociación obtenido aparecen muy importantes solo dos de los cinco criterios de Hofstede (y nueve de Globe) sobre la cultura francesa: alta distancia de poder y rechazo a la incertidumbre. Del proyecto Globe hemos hallado muy importantes los dos anteriores (actitudes sobre el poder y la incertidumbre), y la asertividad; también ha sido útil considerar la importancia de la cultura ideal, como se cree que debería ser la negociación. Igualmente son importantes las dos variables de Hall (1966): cultura monocrónica (agenda ordenada), de bajo contexto comunicativo (precisión de lenguaje escrito). Podría concluirse que hay una cultura de negociación francesa para dirimir diferencias de intereses enraizada en los valores y costumbres que prevalecen en su región.

Pero lo anterior apunta a una limitación del estudio, que justificaría investigaciones posteriores: las diferencias regionales en Francia. Una observación tomada del diario de campo del primer autor al comparar la cultura que observó en Toulouse (sur de Francia) con la de Nancy (noreste), con notables diferencias geográficas, es que la escuela como agente socializador homogeneiza los patrones de negociación en la cultura francesa. Esta sería una hipótesis que proponemos para futuras investigaciones.

La versión interna (francesa) y la versión externa (extranjeros) tienen algunas diferencias, pero también muchas semejanzas. Se ha dicho que desde el interior de una cultura se ven más diferencias; esta es una perspectiva interesante para un análisis preciso más cuantitativo. Posteriores estudios podrían investigar a profundidad las diferencias y semejanzas entre la versión interna y externa.

Otra limitación del estudio es que su naturaleza cualitativa, aunque tiene la ventaja de ser más holística e integradora, podría ser más precisa dando cabida a estudios cuantitativos. El modelo de las veinte categorías de la tabla 3 se puede enfocar y delimitar con variables cuantitativas más "formales" (0gliastri y Quintanilla, 2016) que permitirían hacer un análisis más preciso y comparativo entre los resultados de Francia y los de otros países o culturas. Este es un camino muy promisorio, que ya ha tomado este grupo de investigación.

Un hallazgo importante de este estudio es determinar que en Francia coexisten los dos prototipos de negociador (distributivo e integrativo), y ello podría ser la base para estudios cuantitativos más detallados que identifiquen a los dos prototipos, diferenciando entre hombres y mujeres, generaciones, regiones, niveles jerárquicos y sectores 
de actividad. Esto permitiría adicionalmente explorar a fondo la universalidad de estos prototipos de negociación que surgieron de los estudios anglosajones.

En síntesis, los consejos principales para quienes van a negociar con franceses incluyen: 1) realizar una preparación cuidadosa de la negociación con cifras y argumentos sólidos (en lugar del regateo de propuestas extremas sin base objetiva), lo que le permitirá ser asertivo durante la negociación; 2) mostrar paciencia y buscar un acercamiento gradual; 3) ser flexible sin perder independencia y no tomar las cosas personalmente; 4) mantener las buenas formas; y 5 ) obtener un conocimiento básico de la cultura francesa y de su forma de negociar.

Para los franceses, la principal recomendación es que sean conscientes de los estereotipos y percepciones que se tienen sobre su estilo de negociación, y traten de evitar fáciles interpretaciones negativas en ese sentido, que podrían ser contraproducentes a sus intereses.

Por la importancia de la economía francesa en el comercio mundial, y por el rol socio-económico y político de este país a escala internacional, como, por ejemplo, se observó en las cumbres sobre cambio climático que se celebraron para los Acuerdos de París de 2015 (Clark y Stothard, 2015) y el “One Planet Summit” de diciembre 2017 (Breeden y Peltier, 2017; Cantón, 2017) en París, el saber negociar con los franceses representa una ventaja significativa para las organizaciones. Esperamos que este artículo ayude a facilitar las negociaciones interculturales con franceses, y que provea información útil a los franceses sobre la manera como son percibidos e interpretados por los extranjeros.

\section{Referencias}

Adair, W., Brett, J., Lempereur, A. et al. (2004). Culture and negotiation strategy. Negotiation Journal, 20(1), 87-111.

Agar, M., and MacDonald, J. (1995). Focus groups and ethnography. Human Organization, 54(1), 78-86. https://doi.org/10.17730/humo.54.1.x102372362631282

Aslani, S., Ramirez-Marin, J., Brett, J. et al. (2016). Dignity, face, and honor cultures: A study of negotiation strategy and outcomes in three cultures. Journal of Organizational Behavior, 37(8), 1178-1201. https://doi.org/10.1002/job.2095

Azouvi, F. (1998). Descartes. In P. Nora and L. D. Kritzman (eds.), Realms of memory (III): The construction of the French past (pp. 483-522). New York: Columbia University Press. 
Bazeley, P., and Jackson, K. (2013). Qualitative data analysis with NVivo, 2nd ed., Thousand Oaks, Calif.: SAGE Publications Ltd.

Bourdieu, P. (1977). Outline of a theory of practice. Cambridge, UK ; New York: Cambridge University Press.

Breeden, A., and Peltier, E. (2017, December 12). Macron holds a climate summit, and Trump casts a shadow. The New York Times. Retrieved from https://www.nytimes.com/2017/12/12/ world/europe/macron-climate-summit.html

Brett, J. M. (2014). Negotiating globally: How to negotiate deals, resolve disputes, and make decisions across cultural boundaries ( $3^{\text {rd }}$ ed.). San Francisco, CA: John Wiley \& Sons.

Brett, J. M., Adair, W., Lempereur, A. et al. (1998). Culture and joint gains in negotiation. Negotiation Journal, 14(1), 61-86. https://doi.org/10.1023/A:1024610404410

Brett, J. M., Gunia, B. C., and Teucher, B. M. (2017). Culture and negotiation strategy: A framework for future research. The Academy of Management Perspectives, 31(4), 288-308. https://doi.org/10.5465/amp.2015.0195

Brett, J. M., Olekalns, M., Friedman, R. et al. (2007). Sticks and stones: Language, face, and online dispute resolution. Academy of Management Journal, 50, 85-99.

Broome, B. J. (2017). Negotiating the nexus: Symbiotic relationship of theory and practice in conflict management. Negotiation and Conflict Management Research, 10(4), 252-264. https://doi.org/10.1111/ncmr.12105

Campbell, N., Graham, J., Jolibert, A., and Meissner, H. (1988). Marketing negotiations in France, Germany, the United Kingdom, and the United States. Journal of Marketing, 52(2), 49. https://doi.org/10.2307/1251264

Cantón, E. (2017, December 12). Macron implica a los actores económicos en la lucha contra el cambio climático. Retrieved January 30, 2018, from http://www.elperiodico.com/ es/medio-ambiente/20171212/macron-implica-ctores-economicos-lucha-cambio-climatico-6491071

Castel, P., Deneire, M., Kurc, A., Lacassagne, M.-F., and Leeds, C. A. (2007). Universalism and exceptionalism: French business leadership. In J. Chhokar, F. Brodbeck, and R. House (eds.), Culture and leadership across the world: The GLOBE book of in-depth studies of 25 societies (pp. 547-582). New York: Routledge.

Chhokar, J., Brodbeck, F., and House, R. (2007). Culture and leadership, across the world: The GLOBE Book of In-Depth Studies of 25 Societies. Mahwah, NJ: Lawrence Erlbaum Associates.

Clark, P., and Stothard, M. (2015, December 12). COP21: París agreement formally adopted. Retrieved October 24, 2016, from https://www.ft.com/content/8677562c-a0c0-11e58d70-42b68cfae6e4

Cogan, C. (2003). French negotiating behavior: Dealing with La Grande Nation. Washington DC: United States Institute of Peace. 
Crozier, M. (1964). The bureaucratic phenomenon. Chicago, IL: University of Chicago Press. Damasio, A. R. (1994). Descartes' error: Emotion, reason, and the human brain. New York: G.P. Putnam.

D'Iribarne, P. (1994). The honour principle in the "bureaucratic phenomenon". Organization Studies, 15, 81-97. https://doi.org/10.1177/017084069401500104

Druckman, D. (2005). Doing research: Methods of inquiry for conflict analysis. Thousand Oaks, CA: SAGE Publications, Inc.

Duverger, M. (1974). La monarchie républicaine. París: Robert Laffont.

Ebner, N., and Parlamis, J. (2017). Weaving together theory, research, practice, and teaching: A four-dimensional approach to negotiation and conflict management work. Negotiation and Conflict Management Research, 10(4), 245-251.

Fosse, S., Ogliastri, E., and Rendon, M. (2017). When dignity and honor cultures negotiate: Finding common ground. Negotiation and Conflict Management Research, 10(4), 265-285.

Gannon, M. J., and Pillai, R. K. (2012). French wine. In Understanding global cultures: Metaphorical journeys through 31 nations, clusters of nations, continents, and diversity, $5^{\text {th }}$ ed., (pp. 227-246). Thousand Oaks, Calif: Sage.

Giles, C. (2016, October 4). UK slips below France in global economy table. Retrieved October 24, 2016, from https://www.ft.com/content/7508bf1e-8a46-11e6-8cb7-e7ada1d123b1

Glaser, B. G., and Strauss, A. L. (1967). The discovery of grounded theory: Strategies for qualitative research. New York: Aldine de Gruyter.

Glucksmann, A. (1987). Descartes, c'est la France. París: Flammarion.

Graham, J. L., Mintu, A. T., and Rodgers, W. (1994). Explorations of negotiation behaviors in ten foreign cultures using a model developed in the United States. Management Science, 40(1), 72-95. https://doi.org/10.1287/mnsc.40.1.72

Hall, E. T. (1966). The hidden dimension. New York: Doubleday.

Hall, E. T., and Hall, M. R. (1990). Understanding cultural differences: Germans, French and Americans. Yarmouth, Me.: Intercultural Press.

Hofstede, G. (2003). Culture's consequences: Comparing values, behaviors, institutions and organizations across nations. Thousand 0aks: Sage Publications.

Hofstede, G. (2016). France. Retrieved October 28, 2016, from https://geert-hofstede.com/ france.html

Hofstede, G., Hofstede, G. J., and Minkov, M. (2010). Cultures and organizations: Software of the mind. New York: McGraw-Hill.

House, R., Hanges, P., Javidan, M., Dorfman, P., and Gupta, V. (2004). Culture, leadership, and organizations: The GLOBE study of 62 societies. Thousand 0aks: Sage Publications. 
Leung, A. K., and Cohen, D. (2011). Within- and between-culture variation: Individual differences and the cultural logics of honor, face, and dignity cultures. Journal of Personality and Social Psychology, 100(3), 507-526. https://doi.org/10.1037/a0022151

Luo, Y., and Shenkar, 0. (2011). Toward a perspective of cultural friction in international business. Journal of International Management, 17(1), 1-14. https://doi.org/10.1016/j. intman.2010.09.001

Malhotra, D., and Bazerman, M. H. (2008). Negotiation genius: How to overcome obstacles and achieve brilliant results at the bargaining table and beyond. New York, N. Y.: Bantam Dell.

Morrison, T., and Conaway, W. A. (2006). Kiss, bow or shake hands: The bestselling guide to doing business in more than 60 countries, $2^{\text {nd }}$ ed., Avon, MA: Adams Media Corporation.

Newson-Balle, L. (1996). Negotiating with the French. Career Development International, 1(5), 15-20. https://doi.org/10.1108/13620439610130597

Ogliastri, E. (1997). Una introducción a la negociación internacional. La cultura latinoamericana frente a la angloamericana, japonesa, francesa y del Medio Oriente. Monografías de Administración, 49, 1-84. U. de los Andes.

Ogliastri, E. (2000). El estilo negociador de los latinoamericanos. Una investigación cualitativa. Academia. Revista Latinoamericana de Administración, 25, 43-58.

Ogliastri, E., Mc Millen, C., Altschul, C. et al. (1999). Cultura y liderazgo organizacional en 10 países de América Latina: el estudio Globe. Academia Revista Latinoamericana de Administración, 22, 29-57.

Ogliastri, E., and Quintanilla, C. (2016). Building cross-cultural negotiation prototypes in Latin American contexts from foreign executives' perceptions. Journal of Business Research, 69(2), 452-458. D0I link: http://dx.doi.org/10.1016/j.jbusres.2015.06.051

Ogliastri, E., and Zúñiga, R. (2016). An introduction to mindfulness and sensemaking by highly reliable organizations in Latin America. Journal of Business Research, 69(10), 4429-4434. https://doi.org/10.1016/j.jbusres.2016.03.008

Patton, M. Q. (2002). Qualitative research and evaluation methods. Thousand Oaks, Calif.: Sage Publications.

Perrow, C. (1999). Normal accidents: Living with high-risk technologies. Princeton, N.J: Princeton University Press.

Raiffa, H. (1982). The art and science of negotiation. Cambridge, Mass.: Belknap Press of Harvard University Press.

Rendón, M. I. (2004). Cultura francesa de negociación internacional. Tesis de maestría no publicada. Universidad de los Andes, Bogotá, Colombia.

Schwartz, S. H. (1994). Are there universal aspects in the structure and contents of human values? Journal of Social Issues, 50(4), 19-45. https://doi.org/10.1111/j.1540-4560.1994. tb01196.x 
Schwartz, S. H. (1999). A theory of cultural values and some implications for work. Applied Psychology: An International Review, 48(1), 23-47. https://doi.org/10.1111/j.1464-0597.1999. tb00047.x

Ury, W. L., Fisher, R., y Patton, B. (2011). Obtenga el sí: el arte de negociar sin ceder. Gestión 2000. van der Walt, M. (2010). French negotiation culture. ADR Bulletin, 12(1), Article 2. Available at http://epublications.bond.edu.au/adr/vol12/iss1/2.

Van Hoof, B., Ogliastri, E., Bernal, J., y García, A. (2005). Relaciones interculturales. Las negociaciones entre colombianos y holandeses. Monografías de Administración, 83, 1-115.

Walton, R. E., and McKersie, R. B. (1991). A behavioral theory of labor negotiations: An analysis of a social interaction system. Cornell University Press.

Weiss, S. E., \& Stripp, W. (1985). Negotiating with foreign businesspersons: An introduction for Americans with propositions on six cultures (Working Paper 85-6). New York, NY: New York University Graduate School of Business.

\section{Anexo. Guía de entrevistas}

País o cultura con la cual se negoció:

Nombre del entrevistado:

Cultura o país de origen:

Antecedentes del entrevistado: origen, profesión, tipo de experiencia, sector:

Nombre y país de quien hizo la entrevista:

Piense concretamente en una negociación formal (compra o venta, resolución de un conflicto, conversaciones para llegar a un acuerdo de política común, etc.), concreta en que haya participado y que involucre personas o entidades de dos países.

a. ¿Cuáles fueron los antecedentes (los intereses) que motivaron esta negociación? (¿Qué le pasaría a cada uno si no se llegaba a un acuerdo; cuáles eran sus alternativas?).

b. ¿Cómo fue la preparación de la negociación? ¿Cuáles fueron las pre-negociaciones, aproximación a las partes?

c. ¿Cómo se decidió quién iba a negociar, cuál sería la agenda, dónde se iba a negociar?

d. ¿Cómo se inició la negociación? (¿Fue un proceso de regateo con una demanda excesiva al principio?) ¿Quién abrió la negociación? ¿De qué manera se estable- 
cieron las dos aperturas de cada parte? ¿Se buscaron y establecieron criterios, objetivos, o fue un mero regateo de posiciones?)

e. ¿Cuáles fueron los principales incidentes de la transacción? ¿Cómo consiguió usted los puntos más importantes?

f. ¿Cómo fue el cierre y el acuerdo? ¿Fue un buen acuerdo? (satisfactorio para las partes, duró por largo tiempo, etc.).

g. ¿Qué fue lo que más le llamó la atención de esta experiencia? ¿Lo que más le gustó? ¿Lo que menos le gustó? ¿Cree usted que la gente del otro país es semejante a usted? (¿En qué?) Es diferente a usted (¿En qué?). ¿Cómo son?

h. ¿Cree usted que esta fue una experiencia típica? ¿Ha tenido experiencias muy diferentes a esa (con personas del mismo país o cultura)?

i. Si usted tuviera que volver a hacer esta misma negociación: ¿Qué haría diferente a lo que hizo? ¿Qué consejos le daría a otra persona (un colega o un amigo) que vaya a negociar a ese otro país?

j. En síntesis: ¿cómo negocian por lo general los de ese país? ¿Cuál es la diferencia con la negociación que acaba de contar? 
